\title{
Solubilization of docetaxel in poly(ethylene oxide)-block-poly(butylene/styrene oxide) micelles
}

\author{
Mahmoud Elsabahy ${ }^{1}$, Marie-Ève Perron ${ }^{1}$, Nicolas Bertrand ${ }^{1}$, Ga-er $\mathrm{Yu}^{2}$ and \\ Jean-Christophe Leroux ${ }^{1 *}$
}

${ }^{*}$ Canada Research Chair in Drug Delivery, ${ }^{1}$ Faculty of Pharmacy, University of Montreal, C.P. 6128, Succ. Centre-Ville, Montreal (QC) H3C 3J7, Canada

${ }^{2}$ Advanced Polymer Materials Inc., 5020 Fairway, Suite 224, Montreal (QC) H8T 1B8, Canada

${ }^{*}$ To whom correspondence should be addressed

Phone: (514) 343-6455

Fax: (514) 343-6871

Email: Jean-Christophe.Leroux@umontreal.ca 
The kinetic modeling was applied by using the following equation S1:

$$
\frac{M_{t}}{M_{\infty}}=\left[P_{o}\left(1-\exp \left(-K_{d} t\right)\right]+\left[P_{m}\left(1-\exp \left(-K_{m} t\right)\right)\left(1-\exp \left(-K_{d} t\right)\right)\right]\right.
$$

Where $\mathrm{P}_{\mathrm{o}}$ and $\mathrm{P}_{\mathrm{m}}$ are constants related to the amount of drug initially present in the donor compartment (free DCTX) and in the micelles, and $\mathrm{K}_{\mathrm{d}}$ and $\mathrm{K}_{\mathrm{m}}$ are rate constants for diffusion out of donor compartment and micelles, respectively (Figure S1). The $\mathrm{K}_{\mathrm{d}}$ used for all simulations was determined by fitting the equation on DCTX release profile with $\mathrm{K}_{\mathrm{m}}=0$.

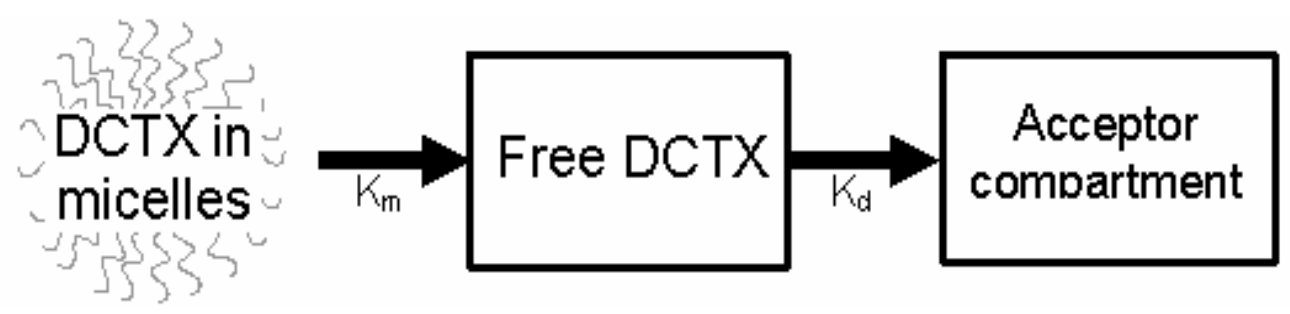

Figure S1. Kinetic model for DCTX release from micelles in jacketed Franz diffusion cells.

\section{Reference:}

1. Jacquez, J.A. Compartmental analysis in biology and medicine. First ed., Elsevier. 1972, Amsterdam: Elsevier Publishing Company. p.237. 